\title{
CRITICAL MOMENTS IN A COACHING CASE STUDY: ILLUSTRATION OF A PROCESS RESEARCH MODEL
}

\author{
Erik de Haan \\ Ashridge Business School and VU \\ University, Amsterdam
}

\author{
Christiane Nieß \\ Cologne Graduate School in \\ Management, Economics, and \\ Social Sciences
}

\begin{abstract}
Descriptions of critical moments of coaching, defined as exciting, tense, or significant moments from the time spent in the coaching conversation experienced by an executive coach and one of his clients, are analyzed and compared. Positioned within a tradition of analyzing critical-moment descriptions, the study makes use of data collected immediately after mutual coaching sessions. Both coach and client recorded one or more critical moments that had occurred in each coaching session, thereby providing data collected over time and allowing a direct comparison of the coach's and the client's critical-moment experiences. Results suggested that in almost half of the descriptions, the coach and the client referred to the same moments as being critical in the coaching sessions. Although the coach mostly described moments of self-doubt as being critical, the client focused on moments of new learning and a positive change in the coaching relationship. The results of this study were consistent with earlier work on critical moments in executive coaching. The study also offers an in-depth analysis of the coaching process over time, as experienced by both client and coach.
\end{abstract}

Keywords: executive coaching, critical moments, case studies, qualitative research, longitudinal study

Executive coaching is rapidly becoming an established area of professional practice with recognized professional bodies, formal accreditation and codes of conduct. Among the many forms of intervention within organization-development (OD) and consulting psychology, it has probably been one of the fastest growing (Hall, Otazo, \& Hollenbeck, 1999). As the use of coaching has become more pervasive, expectations have risen (Ely et al., 2010), because the approach can be highly customized around the needs of individual executives or of particular organizational units.

Erik de Haan, Ashridge Center for Coaching, Ashridge Business School, Berkhamsted, United Kingdom and VU University, Amsterdam; Christiane Nieß, Cologne Graduate School in Management, Economics, and Social Sciences, Köln, Germany.

Erik de Haan is Professor of Organization Development and Coaching.

Correspondence concerning this article should be addressed to Erik de Haan, Ashridge Center for Coaching, Ashridge Business School, Berkhamsted, Herts HP4 1NS, United Kingdom. E-mail: Erik.deHaan@Ashridge.org.uk 
Client organizations are entitled to know about the effectiveness of this popular intervention, and trainee coaches (as well as mature ones) need information on outcomes and effectiveness as much as on professionalism and ethics, so that they can adjust their interventions and style accordingly. Moreover, they need information from actual case studies so that they can appreciate the challenges and dilemmas they might encounter and consider alternative ways of dealing with them.

\section{Summary of Outcome Research}

Over the last 15 years, empirical research on coaching outcome has really taken off (for a detailed overview of the coaching outcome research literature to date, see de Haan, Duckworth, Birch, and Jones, 2012). The main conclusions from effectiveness studies are that those researchers who did not use a control group (e.g., Kombarakaran, Yang, Baker, \& Fernandes, 2008; McGovern et al., 2001; Olivero, Bane, \& Kopelman, 1997; Peterson, 1993; Schlosser, Steinbrenner, Kumata, \& Hunt, 2006; Thach, 2002; Wasylyshyn, Gronsky, \& Haas, 2006) have tended to find large effects (generally larger than those found in psychotherapy), while the more rigorously designed studies involving control groups (such as those by Allen, Eby, Poteet, Lentz, \& Lima, 2004; Evers, Brouwers, \& Tomic, 2006; Smither, London, Flautt, Vargas, \& Kucine, 2003) have found only small effects, generally smaller than those found in psychotherapy (Wampold, 2001). However, these studies include research conducted using mentors or internal coaches, while many of the studies without control groups involved more significant programs with qualified professional coaches, which may also have been a factor in the higher effect sizes. It appears that if the client alone is the focus of the study (versus, for example, organizational or team-level results), the outcomes tend to be quite positive, whereas if controls are included for perceptual and research artifacts, this effect is much smaller in size, although still positive.

For understanding the impact and contribution of executive coaching interventions, we argue that it is not enough to just understand general effectiveness or outcome. We believe it is also important to inquire into the underlying coaching processes themselves, the active ingredients, from the perspectives of both clients and coaches, and, if possible, those of their organizational peers and sponsors as well. As part of the outcome research literature, some studies have indeed looked at possible active ingredients (e.g., Stewart, Palmer, Wilkin, \& Kerrin, 2008; Baron \& Morin, 2009; Boyce, Jackson, \& Neal, 2010; de Haan et al., 2012). These studies all argue that the relationship between coach and client is the single largest predictor for coaching outcomes that we know, and, moreover, that this relationship mediates most of the effect of other factors.

Outcome or effectiveness research reduces the whole of the coaching intervention to only one or a few numbers, such as psychometric variables or 360-degree feedback ratings. Outcome research has generally been silent on what happens within a coaching relationship, such as the many gestures, speech acts, and attempts at sense making that make up the whole of the intervention. At best, existing coaching outcome research can tell us, in a statistical manner, how the full sum of all those coaching sessions taken together may contribute to a digit on a Likert scale; at their worst, such studies may not even tell us that. What interests us in this study is how outcomes are achieved within the coaching intervention, that is, within and between individual coaching conversations. This is the realm of so-called suboutcomes (Rice \& Greenberg, 1984) or outcomes achieved in moments or sessions of coaching.

\section{Summary of Process Research With Critical Incidents}

Research on coaching process is not as straightforward as coaching-outcome research. Although reducing the whole of a coaching relationship to one or a few quantifiable outcomes (e.g., ratings by the coach, the client, the client's boss, an independent observer) allows a clear-cut and specific definition of that variable, when it comes to process, it is necessary to address multiple variables and suboutcomes (Rice \& Greenberg, 1984). 
Process research is not without its challenges. Studying an ongoing process, for example, can in itself influence that process and thus make it harder to study. Despite the difficulties with process research, it is of vital importance for coaching practitioners to better understand what is perceived to have happened in conversations between coach and coachee, the aspects of the interchanges in coaching to which each partner pays attention, and what each participant thinks has been achieved through engaging in the coaching.

Several quantitative studies on what had been experienced as critical incidents or critical moments by clients and/or coaches have been published, including those by de Haan (2008a, 2008b), Day, de Haan, Blass, Sills, and Bertie (2008), and de Haan, Bertie, Day, and Sills (2010a). Studies of coaches' and clients' independent descriptions immediately after coaching sessions have also been reported (de Haan, Bertie, Day, \& Sills, 2010b) as well as studies on the retrospective accounts of coaching by organizational third parties (de Haan \& Nie $\beta, 2011$ ). From such real-life observations and case studies, coaches can learn how the coaching intervention is responded to by clients and coaches, and where potential discrepancies in perceptions or other pitfalls may occur. The following is an overview of this earlier research undertaken by the Ashridge Critical-Moment Study Group, in which a "critical moment" was defined throughout the studies as "an exciting, tense or significant moment experienced during coaching sessions" (de Haan 2008a, p. 92):

- De Haan (2008a) collected 80 descriptions by less-experienced internal and external coaches of critical moments they perceived in their coaching efforts. Approximately $75 \%$ of the coaches who participated in this study had recently completed a full-year program in management consulting, and about $25 \%$ were beginning independent coaches. Content analysis showed that all critical moments could be interpreted as expressing doubts of coaches.

- De Haan (2008b) collected 78 descriptions of critical moments from experienced coaches with at least eight years of experience in the field. Content analysis showed that all critical moments could be expressed as anxieties of coaches-in other words, that these experienced coaches were grappling with recurring struggles in their client work.

- Day et al. (2008) collected 49 descriptions of critical moments from another very experienced group through more in-depth telephone interviews and studied the temporal process around critical moments. Content analysis showed that an experienced "rupture" in the relationship (e.g., misunderstanding, anger, recontracting and referral, withdrawal or termination) could be found around every critical moment, and that, in most cases, the presence or absence of ongoing and shared reflection determined whether the rupture in the relationship was overcome or not.

- De Haan et al. (2010a) collected 59 descriptions of critical moments from clients of coaching. Content analysis showed that clients reported that new realizations and insights were most critical in their experience of coaching. This finding contrasted with what was found in De Haan (2008a) and De Haan (2008b) for the executive coaches.

- De Haan et al. (2010b) collected descriptions of 86 critical moments from clients and coaches immediately after specific coaching sessions, i.e., after the coaching had ended. Also in this study, a re-coding of all earlier datasets was undertaken by four coders using a simple coding structure, that is summarized in Table 1 . All codes were accompanied by a brief explanation and coders were requested to use a single code per critical moment. The recoding confirmed that, for inexperienced coaches, the code around coaches' doubts (Code 12 in Table 1) was used most, in 56\% of the descriptions, which is much higher than in any of the other data sets. Similarly, the recoding confirmed that, for experienced coaches, the most frequent code was coaches' anxieties (Code 10 in Table 1), in 22\% of the descriptions. In the new study, both coaches and clients reported new realizations and insights as being most critical in their direct experiences of coaching. With the recoding, the most frequently used codes were Codes 1 and 2 in Table 1, which best fitted at least $40 \%$ and up to $62 \%$ of the critical-moment descriptions. This led to the hypothesis of different but overlapping sets of critical-moment descriptions in the five data sets. In the data sets of de Haan (2008a, 2008b) and Day et al. (2008), coaches provided critical moments from their coaching work over the last year, and so they may have mostly contributed examples of "exceptional circumstances" such as ruptures in coaching relationships. In de Haan et al. (2010a), clients referred only to a single coaching relationship, and in de Haan et al. (2010b), clients and 
Table 1

The 12 Codes $^{a}$ Used to Categorize Coaching Critical Moments

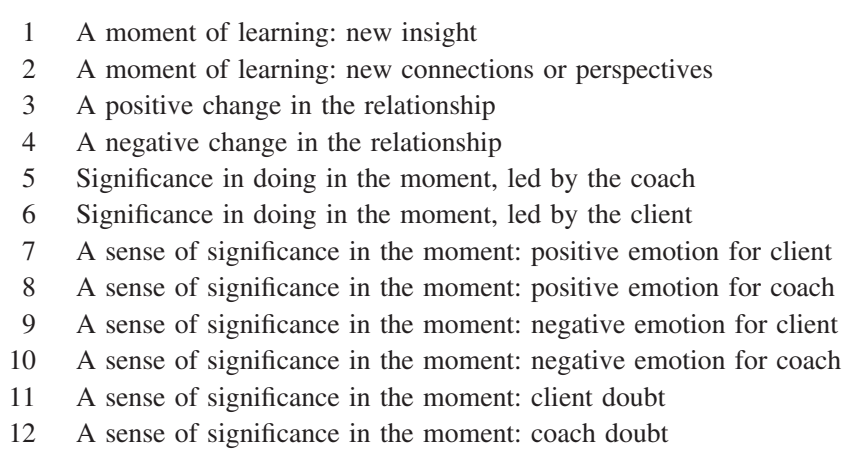

${ }^{\text {a }}$ See de Haan et al. (2010b).

coaches referred only to a single coaching session and hence may have been referring to everyday coaching sessions rather than to coaching in exceptional circumstances. This hypothesis explained why the two groups of data sets were so fundamentally different and consistently negatively correlating, when coded using the codes in Table 1.

In summary, and comparing the findings between coaches' critical moments and clients' critical moments, de Haan et al. (2010b) found that (a) in 53\% of cases, clients and coaches referred to the same moments when asked independently what was critical in their shared conversation; and (b) in most everyday executive coaching, clients and coaches identified the same broad patterns as being most critical, with the highest occurrence of realizations and new insights as aspects of critical moments.

\section{Summary of Case-Study Process Research}

Another way of doing process research is through complete case studies. In other helping professions, such as psychotherapy, there has been a long tradition of case study analysis, beginning with Breuer and Freud (1895; short cases of 10 to 60 pages each) and Freud (1905; first book-length case study). Therapeutic relationships, told in the words of both therapist and client, go back to Yalom and Elgin (1974), who codescribed and copublished their therapeutic encounters. One of the first studies to investigate therapists', patients', and even observers' agreement concerning a therapeutic session was conducted by Mintz, Auerbach, Luborsky, and Johnson (1973). It was found that there was a reasonable consensus concerning the descriptions of the patient's emotional states, while agreement was rather poor when evaluating the therapeutic relationship and the "goodness" of the session. After decades of research on the topic, Weiss, Rabinowitz, and Spiro (1996) published a literature review including the findings of 41 such studies. Taken together, these studies indicate that there is a great variability in therapists' and clients' agreement in the evaluation of problems, processes, and outcomes of therapy. For a more recent example of a case study that is described from the perspective of both therapist and client, and then analyzed by an independent researcher, see Mackrill (2011).

Over recent years, the study of the therapeutic process and of critical moments has been given a new impulse by the discovery of "sudden gains" in some $40 \%$ of patients undergoing once-weekly psychotherapy and the convincing indications that those patients with sudden gains suffer less relapse than other patients (e.g., Tang \& DeRubeis, 1999). Sudden gains, or large symptom 
improvement from one session to the next, have now been demonstrated in cognitive-behavioral, supportive-expressive, and psychodynamic therapy, and for different disorders (see Tang, DeRubeis, Hollon, Amsterdam, \& Shelton, 2007; Present et al., 2008). If they are as significant to longer-term outcome as they seem, then it becomes still more important to inquire into individual sessions and the experience of clients within those sessions.

Although there is considerable research evidence on therapists' and clients' perceptions of the therapeutic process, we found only a couple of case study reports within the executive coaching literature (Appendix C in de Haan, 2008c; Levenson, 2009), and they were all written by coaches. In Appendix C of de Haan (2008c), a 12-page summary of a five-session executive-coaching assignment is provided. This includes a short review by the client. Levenson (2009) gives an overview of 12 successful case studies and analyzes factors that contribute to success, finding that the most important one related to transfer of coaching to the workplace.

\section{This Research: Process Research With Critical Incidents in a Single Case Study}

Lowman's (2001; see also Lowman \& Kilburg, 2011) proposal of a case-study-informed coaching literature seems to have been little heeded in the 10 years since it appeared. To our knowledge, the present article is the first full case study written by both coach and client, based on their critical-moment descriptions, similar to the critical incidents reported in de Haan et al. (2010b). It was not written as a single common case study, precisely because we wanted to compare and contrast the independent views of the client and the coach. For this reason, the coach and client made independent notes right after the sessions (or at least on the same day), similar to the process in Yalom and Elgin (1974). Only after the full 10 sessions of coaching did the coach and client have a chance to read each other's responses, and they then wrote a response to the other person's perceptions. Only after this information was completed did they decide to write the article together to give an honest, real-life, parallel account of a developing coaching relationship. Some personal details of the coach and the coachee were suppressed from the accounts, but, otherwise, they are verbatim and thus faithful accounts of the critical moments that the coach and client encountered in their work together.

The present study brings together both traditions of process research in the coaching literature: the study of critical moments and case study analysis. In this way, we hope to contribute to a better understanding of suboutcome and of that best predictor of coaching outcome: the coaching relationship. In doing a formal analysis of critical-moment descriptions coming from coach and client in a shared coaching assignment, we are testing the following hypotheses, which we base on earlier publications in the field.

Hypothesis 1: Coach and client will refer to the same moment with a frequency that is significantly above chance. De Haan et al. (2010b) showed that, in their data set, 53\% of descriptions referred demonstratively to the same moment in conversation, which is well above chance. This would be in contrast to what is often reported in psychotherapy research, namely that psychotherapist and patient rarely report the same moments from their common conversations (e.g. Tallman \& Bohart, 1999).

Hypothesis 2: Coach descriptions and client descriptions will be coded broadly similarly by independent coders, as shown in earlier research exploring experienced coach (de Haan, 2008b) and client (Day et al., 2008) descriptions of critical moments. In particular, the coding will reveal consistent broad differences, including

a. coaches focusing more on anxieties and doubts, and

b. clients focusing more on insights and realizations.

Hypothesis 3: Depending on the degree and significance of relational "ruptures" in the material, there should be evidence for the two types of coaching distinguished in de Haan et al. (2010b) as "run of the mill" or everyday coaching versus coaching in the presence of "exceptional tensions". 
Hypothesis 4: Analysis of longitudinal development will show that, over the course of the coaching, the conversations have a differential impact, in a manner similar to the dose-effect relationship found in psychotherapy (e.g., Howard, Kopta, Krause, \& Orlinski, 1986). On the basis of this evidence from psychotherapy-outcome research, we would expect client outcomes such as new insight to decrease from Session 1 onward.

When setting out to do case studies, it is important to have a theoretical framework that includes the study's questions, propositions, units of analysis, logic linking data to propositions, and criteria for interpreting the findings including the potential for generalization (Yin, 1994; Lowman \& Kilburg, 2011). For this purpose, one of us (Erik de Haan) carried out two pilot case studies of 10 sessions each with two different clients. These analyses contributed to the formulation of the hypotheses outlined here.

\section{Method}

Data were collected for the present case study on the basis of 10 coaching conversations between the executive coach and the client.

\section{Setting}

During an initial preliminary meeting requested by the client, the coach and client agreed to have ten 90-min coaching sessions over a period of 7 months. Help was requested by the client concerning topics of career choice and personal development, especially in academia. The first three of the coaching sessions were face-to-face in the United Kingdom, and the other seven were over the phone, since the coach was based in the United Kingdom and the client was in the Netherlands. The sessions were conducted in English, the second language of both client and coach. Sessions took place at approximately three-week intervals. No rescheduling was needed. Session times were held as scheduled, except for two occasions when the coach was late on the call (Session 5) and when the coach had overlooked the time difference between the United Kingdom and the Netherlands, and had to be reminded of the starting time of the session (Session 7). That particular session started an hour late, but could still be held and was of the agreed-upon length. The fee for the sessions was reduced to $£ 50$ per session, payable to a global charitable organization, because the client committed-like the coach-to the research task.

\section{Procedure}

Both the coach and the client were asked, on the same day after each session, to write down one or two "critical moments" of that session (i.e., a few paragraphs of writing), with the understanding that a "critical moment" was again defined to be an exciting, tense, or significant moment from the time spent in the coaching session (see de Haan, 2008a, and consecutive papers). We have provided all literal descriptions of the critical moments as an Appendix to this article in order to convey the type of data collected in the case study and to illustrate the participants' fluency in English as a second language. The issue of working in multiple and nonnative languages is becoming more important as coaching becomes more global. This allows the reader to examine possible subtleties in language that may have had an impact on (mis)understanding.

The client was informed that the research would consist of content analyzing the various critical-moment descriptions and of comparing client descriptions with coach descriptions from session to session and that this analysis would only be done after the 10 sessions had been completed. Anonymity and permission from the client in case of eventual publication were obtained from both parties prior to the beginning of the coaching.

\section{Participants}

The executive coach was an accredited coach in his late 40s with 15 years of experience in this field, while the client was in her mid-20s and was a Master of Science (MSc) student in theoretical 
psychology in the Netherlands. The client finished her MSc degree in the Netherlands during the course of the assignment to become a doctoral-level student in a graduate school in Germany. The client had no previous experience of executive coaching. Coach and client did not discuss (either in conversation or in correspondence) any material of the coaching sessions, or the sessions themselves, outside of the sessions.

\section{Focus of the Coaching}

The coach and coachee had two research project meetings that were clearly separate from the coaching sessions. There was no other contact but coaching sessions until the week before the 10th session, when they had one more research project meeting; so for most of the 7 months of the coaching, there were no other interests between them. After the first session, the coach also committed himself to writing a formal written contract for the 10-session coaching assignment, in which the following two objectives were described:

1. You — the client —would like to use our sessions to think about your work on your Master's Thesis, which you are now preparing and which looks like an interesting challenge.

2. You would like to find guidance - or guide yourself-as to how to approach your longer term personal development and career. You mentioned four "career paths" that may be open to you, and you would like to understand them, yourself and your choices better before you embark on one or several of these.

These objectives have been summarized in writing by the coach, and the client agreed to them at the second session, requesting no further changes. Much of the work in the sessions was around finding one's feet in a competitive and ambitious academic environment, holding one's own in that environment, and progressing through to the next "rank" while continuing to progress other business interests.

\section{Procedure}

After each of the sessions, both the coach and the client wrote down one or two critical moments of that session, a critical moment being defined as "an exciting, tense or significant moment from the time spent in the coaching session." This procedure resulted in 32 critical-moment descriptions, 14 by the client and 18 by the coach, which were then given to four independent raters (not the authors). The raters were also given 12 codes for classifying coaching critical moments, which have been successfully used with all previous data sets (e.g., de Haan et al., 2010b; see Table 1).

After collecting all critical-moment descriptions and deciding to write up the coaching intervention as a case study, client and coach worked together to provide a phenomenological analysis of the critical-moment descriptions per coaching session (see Appendix).

\section{Results}

Hypothesis 1 asked whether coach and client referred to broadly the same moments as being critical in the coaching conversation. To give one example, if one looks at the critical moments in the eighth session (see Appendix) one can conclude that coach and client were clearly referring to the same moment as being critical in this (the eighth) session, namely the discussion about running out of steam and the sense of having completed the contract already.

Of the 32 critical-moment descriptions, there are 15 (47\%) that, pairwise, clearly referred to the same moment in the session. Specifically, there was one "shared critical moment" in every session from the third to the ninth (i.e., seven in total), and a second match in the sixth session. This finding, which can be checked with the help of the Appendix, offers support for the notion that coach and client experience broadly the same moments in the coaching conversations as being critical.

Hypothesis 2 suggested that the coding of the incidents against the defined categories would be similar among the independent raters. To estimate the degree of agreement between the four raters, Cohen's Kappas were calculated and resulted in a minimum of 0.25 and a maximum of 0.31 , 
suggesting moderate agreement among raters (Landis \& Koch, 1977). This provides support for Hypothesis 2. The total incidence rates of the 12 codes are reported in Figure 1 for the full data set and for the separate data sets of client and coach critical-moment descriptions. Codes 1, 3, and 10 had the highest prevalence; however, the relative prevalence of these three codes was very different in the data provided by the client and coach. Moreover, coding of client and coach data anticorrelates $(r=-0.44)$, in distinction to another data set where moment descriptions were taken straight after the coaching sessions (de Haan et al., 2010b) and where this same correlation was $r=+0.69$. Hence it makes the most sense here to analyze client and coach data separately, as also suggested by Hypotheses $2 \mathrm{a}$ and $2 \mathrm{~b}$.

Hypothesis $2 \mathrm{a}$ stated that the coach's critical moments would be likely to revolve around anxieties and doubts, as included in Codes 10 and 12. To Test Hypothesis 2a, two paired $t$ tests, as well as Wilcoxon signed-ranks tests, were conducted (see Table 2). The $t$ tests were conducted using all critical moment descriptions, rather than only those moments that coach and client both responded to, since the coach may have referred to moments of anxiety and doubt that the client did not even identify as a critical moment.

In order to test Hypothesis 2a, we compared whether the mean frequency of Codes 10 and 12 employed by all of the four raters was higher for the coach's critical-moment descriptions than for the client's critical-moment descriptions, using one-tailed testing. Results revealed that the four raters $(N=4)$ used Code 10 (coach's anxiety) significantly more often to code the coach's critical-moment descriptions $(M=3.75, S D=1.26)$ than to code the client's critical-moment descriptions $(M=0.25, S D=0.50 ; t[3]=5.42, p<.01)$. In the same manner, the four raters $(N=$ 4) used code 12 (coach's doubt) significantly more often to code the coach's critical-moment descriptions $(M=3.25, S D=0.96)$ than to code the client's critical-moment descriptions $(M=$ $0.00, S D=0.00 ; t[3]=6.79, p<.01)$. The results thus support Hypothesis 2a, stating that, in the coding, coaches' critical moments are significantly more often attributed to anxieties and doubts than clients' moments.

Hypothesis $2 \mathrm{~b}$ suggested that clients' critical moments, on the other hand, mainly have to do with insights and realizations. Two more paired $t$ tests were conducted to test whether raters used Codes 1 (insights) and 2 (perspectives) more often to code the client's critical moments than to code the coach's critical moments, also using one-tailed testing. Results support the notion that the four raters $(N=4)$ used Code 1 (insights) significantly more often to code the client's critical-moment descriptions $(M=3.50, S D=1.00)$ than to code the coach's critical-moment descriptions $(M=$ $1.75, S D=0.50 ; t[3]=3.66, p<.05)$. Similarly, the four raters $(N=4)$ used Code 2 (perspectives)

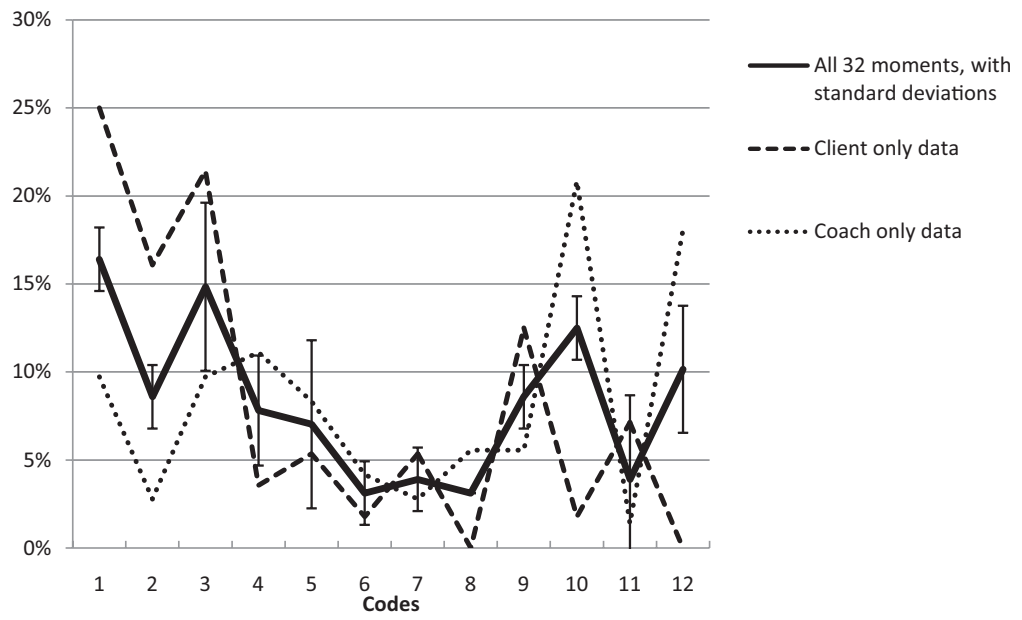

Figure 1. Percentage of times each of the 12 codes was assigned by all four coders for (a) the full data set, (b) client critical-moment descriptions, and (c) coach critical-moment descriptions. 
Table 2

$\mathrm{T}$ Tests and Wilcoxon Signed-Rank Tests Comparing Frequency of Codes for Client and Coach

\begin{tabular}{|c|c|c|c|c|c|c|}
\hline & \multirow[b]{2}{*}{$M$} & \multirow[b]{2}{*}{$S D$} & \multicolumn{2}{|c|}{$t$ test } & \multicolumn{2}{|c|}{$\begin{array}{l}\text { Wilcoxon signed- } \\
\text { rank test }\end{array}$} \\
\hline & & & $T$ & $p$ & $Z$ & $p$ \\
\hline \multicolumn{7}{|l|}{ Comparison 1} \\
\hline Code 10 , client & 0.25 & 0.50 & & & & \\
\hline Code 10 , coach & 3.75 & 1.26 & $5.42^{* * *}$ & 0.01 & $1.83^{*}$ & 0.03 \\
\hline \multicolumn{7}{|l|}{ Comparison 2} \\
\hline Code 12 , client & 0.00 & 0.00 & & & & \\
\hline Code 12 , coach & 3.25 & 0.96 & $6.79^{* *}$ & 0.01 & $1.84^{*}$ & 0.03 \\
\hline \multicolumn{7}{|l|}{ Comparison 3} \\
\hline Code 1 , client & 3.50 & 1.00 & & & & \\
\hline Code 1 , coach & 1.75 & 0.50 & $3.66^{*}$ & 0.02 & $1.84^{*}$ & 0.03 \\
\hline \multicolumn{7}{|l|}{ Comparison 4} \\
\hline Code 2, client & 2.25 & 0.96 & & & & \\
\hline Code 2, coach & 0.50 & 0.58 & $2.33^{*}$ & 0.05 & $1.63^{*}$ & 0.05 \\
\hline
\end{tabular}

Note. $\quad N=4$.

${ }^{*} p<.05 .{ }^{* * *} p<.01$.

significantly more often to code the client's critical-moment descriptions $(M=2.25, S D=0.96)$ than to code the coach's critical-moment descriptions $(M=0.50, S D=0.58 ; t[3]=2.33, p<.05)$.

To additionally Test Hypotheses $2 \mathrm{a}$ and $2 \mathrm{~b}$, Wilcoxon signed-ranks test were conducted as the nonparametric equivalent of the dependent $t$ test, therefore not relying on normality assumptions. Results generally support the findings obtained, again using one-tailed testing. The four raters $(N=$ 4) used Code 10 (coach's anxiety) and Code 12 (coach's doubt) more often to code the coach's critical-moment descriptions than to code the client's critical-moment descriptions $(z=1.826, p<$ .05 , for anxiety; $z=1.841, p<.05$, for doubt). Moreover, the four raters $(N=4)$ used Code 1 (insights) more often to code the client's critical-moment descriptions than to code the coach's critical-moment descriptions $(z=1.84, p<.05)$. Furthermore, the four raters $(N=4)$ used Code 2 (realizations) significantly more often to code the client's critical-moment descriptions $(z=1.63$, $p<.05)$ than to code the coach's critical-moment descriptions.

Formal hypothesis testing of Hypotheses $2 \mathrm{a}$ and $2 \mathrm{~b}$, using both parametric and nonparametric tests, thus suggested that coaches and clients indeed focus on different aspects of the coaching conversation as being critical. Although the coach's critical moments revolved around anxieties and doubts, the client experienced new insights and realizations as especially critical.

Concerning Hypothesis 3, we found that both client and coach data sets in this study contained moments of ruptures or near-ruptures in Sessions 5 to 7 (see Appendix for full quotations), so that the distinction between "everyday" coaching and "exceptional circumstances" coaching (see de Haan et al., 2010b) was not clear-cut in this data set. We conjecture that this data set is probably a mixture of both of those over time, which would support Hypothesis 3 regarding different data sets for different types of coaching.

We were also interested in the development of the critical moments over the course of the 10 coaching sessions (Hypothesis 4). To analyze the frequency of codes used across sessions, we made use of regression analyses, this time using one-tailed testing, since the hypothesis did not specifically address in which direction an effect was expected. Each of the 12 codes was regressed on the session numbers to give an estimate of a significant change in the use of codes depending on the session. The session number was thus entered into the regression as the independent variable, while each of the 12 codes was entered as the dependent variables in separate regression equations. Analyses controlled for the number of moments per session, which were entered in the second step of each 
of the regression equations. We first tested whether or not classification using Code 1, a new insight, would change in its frequency across sessions, as suggested by Hypothesis 4.

Results offer support for Hypothesis 4, showing that classification using Code 1, a new insight, significantly decreased $(\beta=-0.70, p<.05)$ across sessions (see Table 3 ). These results suggested that the most learning occurred in the first few sessions, while new insights decreased over time. For exploratory purposes, we tested where other changes concerning the critical-moment descriptions occurred over the 10 coaching sessions. Across sessions, classifications using Code 3 , a positive change in the relationship, significantly increased $(\beta=0.68, p<.05)$. This means that the relationship in this coaching case changed in a positive way over time, suggesting that the coach and client may have built an increasingly strong and trusted relationship over the course of the sessions. The only other code to change over sessions was Code 12 (the coach's doubts), which increased, but not significantly ( $\beta=0.57, p<.10$; see Table 3 ). Careful coding of critical-moment descriptions therefore demonstrates that outcomes are different over time and that-at least in this coaching relationship-there are patterns and regularity in the changes over time. More specifically, across sessions, the proportion of new insights in this coaching case significantly decreased, thereby confirming Hypothesis 4.

\section{Discussion}

This case study involved a fairly typical course of ten 90-min coaching sessions occurring within approximately three-week intervals. Many features in the case study were common to other executive coaching work: a written contract with two objectives that was revised over time, a rupture in the relationship in Sessions 5 and 6, perceived healing of the rupture in Session 7, and the emergence of a few core "themes," which are an in-depth reflection within the client of challenges that she faces outside of the sessions. It is the story of a well-contracted, finite coaching relationship with clear objectives and some positive outcomes (in terms of career decisions, self-confidence, and self-understanding), as many others would be (in fact, we have other data sets of a similar nature, which can be obtained from the first author).

\section{Comparison With Previous Critical-Moments Research}

Because this case study is embedded in a history of research on critical moments in executive coaching, it is possible to compare the present findings with those obtained in previous research.

Agreement in perceptions of critical moments. The percentage (47\%) of common critical moments found in this study was very close to the 53\% found in de Haan et al. (2010b) for a completely independent data set. If one assumes that there are hundreds of "moments" in every

Table 3

Increases and Decreases of Frequency of Codes Across Coaching Sessions

\begin{tabular}{|c|c|c|c|c|c|c|c|c|c|c|c|c|}
\hline \multirow[b]{3}{*}{ Predictors } & \multicolumn{4}{|c|}{ Frequency of Code 1} & \multicolumn{4}{|c|}{ Frequency of Code 3} & \multicolumn{4}{|c|}{ Frequency of Code 12} \\
\hline & & $S E$ & & & & $S E$ & & & & $S E$ & & \\
\hline & $B$ & $B$ & $\beta$ & $p$ & $B$ & $B$ & $\beta$ & $p$ & $B$ & $B$ & $\beta$ & $p$ \\
\hline \multicolumn{13}{|l|}{ Step 1} \\
\hline Constant & 4.93 & 1.16 & & & -0.07 & 0.85 & & & -0.47 & 1.01 & & \\
\hline Session number & -0.52 & 0.19 & $-0.70^{*}$ & 0.03 & 0.36 & 0.14 & $0.68^{*}$ & 0.03 & 0.32 & 0.16 & 0.57 & 0.09 \\
\hline \multicolumn{13}{|l|}{ Step 2} \\
\hline Constant & 1.87 & 2.39 & & & -0.89 & 1.96 & & & -3.05 & 2.11 & & \\
\hline Session number & -0.42 & 0.19 & -0.57 & 0.06 & 0.38 & 0.15 & $0.73^{*}$ & 0.04 & 0.40 & 0.17 & $0.72^{*}$ & 0.05 \\
\hline Number of moments & 0.79 & 0.55 & 0.367 & 0.19 & 0.21 & 0.45 & 0.14 & 0.65 & 0.67 & 0.49 & 0.41 & 0.21 \\
\hline
\end{tabular}

Note. $\quad N=4$.

${ }^{*} p<.05$. 
single coaching session, based on Stern's (2004) definition of a "moment" in conversation to last between 2 and $8 \mathrm{~s}$, then the probability of finding the same moment selected would be well under $1 \%$ for every pair of descriptions. Of course there is bound to be quite a lot of repetition, elaboration, and deepening in the moments in a coaching session. Nevertheless, agreement of 47\% (and 53\% in de Haan et al., 2010b) is quite a remarkable result and Hypothesis 1 is supported.

Correlations in coding among data sets. Since there was only one coder (AC) who coded all six data sets in the six studies, we can report only correlation coefficients between distributions of the 12 codes in AC's coding (however, cross-coder correlations yield similar magnitudes). In an exploratory analysis, it was tested whether the frequency of codes used by this one coder correlated across data sets. It was found that the present data set correlates best with the experienced coach-descriptions data set in de Haan (2008b; $r=.57, p<.05)$. However, the separate client and coach data sets correlate better with earlier data sets. The client data correlated $(r=.56 ; p<.05)$ with the client data in de Haan et al. (2010a) and also with $(r=.67 ; p<.05)$ the client data in de Haan et al. (2010b). The coach data correlated with $(0.75<r<.78 ; p<.01)$ the three coach-descriptions data sets in de Haan (2008a, 2008b) and Day et al. (2008). Interestingly, these coach data have correlation zero with the coach data in de Haan et al. (2010b), which have been found to correlate well with the client data in that study and in de Haan et al. (2010a). We think that the reason for this is that both client and coach data sets in this study contain moments of ruptures or near-ruptures in Sessions 5 to 7 (as previously described), so that the choice between "everyday" coaching and "exceptional circumstances" coaching (see de Haan et al., 2010b) is not clear-cut in this data set. We conjecture that this data set is probably a mixture of both of those over time.

Frequency of codes used for coach and client critical moments. The codes used in this study to classify the coach's critical moments most frequently were Codes 10 and 12 (see Table 1), anxiety and doubt of the coach. The client's critical moments, however, were most often classified with three codes (Codes 1, 2, and 3; see Table 1), thus reflecting moments of learning and a positive change in the coaching relationship. These findings are very similar to those obtained in previous studies. Although coaches most often report their own anxieties and doubts in their critical moments (de Haan, 2008a, 2008b), clients tend to report moments of new learning as most critical in their coaching experience (de Haan et al., 2010b). What is additionally noticeable is that the coach and client data are mirrored for Codes 7 and 8 , for 9 and 10, and also for 11 and 12, respectively (see Table 1 for brief descriptions of the codes). Both coach and client focused more on their own emotions and doubts rather than on those of their counterparts, as in the earlier studies.

Shared critical moments. As noted, 15 of the 32 critical-moment descriptions referred to the same moment in the session. This incidence rate of "shared critical moments" of $47 \%$ is very similar to what was found in the other real-time comparison study (de Haan et al., 2010b) in which shared moments made up 53\%. Again, we found an average of approximately one shared critical moment per session. The sessions that did not have a shared critical moment in this study were the first two sessions and the last session. In de Haan et al. (2010b), all of the sessions that were measured were midrange (neither beginning nor ending sessions), so that could be a possible reason for the slight drop in occurrence of shared moments.

\section{Limitations and Directions for Future Research}

We realize that this study only encompasses a single coaching assignment and that there are features that may hinder generalizability of this study. The study does not revolve around executive coaching in the strict sense of that term: The client was without leadership responsibility and fully trained as an occupational psychologist, which will have influenced her particular views and expectations of coaching. In addition, in terms of the initial contract, the objectives look more relevant to career counseling than to executive coaching. However, the actual content of the sessions and the dynamic during the sessions was much more reminiscent of executive coaching (see Appendix). Moreover, we believe that occurrences in this relationship and in the critical moments are typical enough for our conclusions to suggest relevance for other executive coaching relationships. This is supported by the high level of agreement found with other studies of executive coaching relationships (e.g., de Haan et al., 2010a, 2010b) conducted with entirely different clients. We therefore believe that the 
present process research is a good model for doing more systematic studies of coaching assignments in terms of critical moments, with the aim of better understanding the emergence of change and learning within coaching sessions.

Professionals in the field and trainee coaches need more real-life cases across the whole spectrum of executive-coaching assignments, not just vignettes of purely positive (e.g., Levenson, 2009) or purely negative (e.g., Berglas, 2002) case examples. We believe that critical-moment analysis is a helpful way to inquire into individual coaching relationships and compare their moment-by-moment or session-by-session outcomes across researchers and samples. We hope that more researchers will take up the same, or similar, methodology and explore other series of 10 or more coaching sessions in terms of critical moments for client and coach. We will then be able to assemble further evidence in terms of longitudinal dynamics and outcomes that one is likely to expect through executive coaching. In addition, more phenomenological analysis is needed on the basis of published case studies to check patterns and to inquire into topical themes, such as-in the case of this study - coaching in a second (or third, etc.) language or coaching in culturally diverse settings. For these purposes, it is useful to have a process-research model that has already been employed for the analysis of many hundreds of critical-moments descriptions and that has been shown to be transferable across a variety of different settings and participants (de Haan et al., 2010b).

\section{Conclusions}

Content analysis of one longitudinal case study, as seen from the perspectives of both client and coach, has demonstrated that earlier regularities found with hundreds of clients' and coaches' critical-moment descriptions from as many coaching relationships can be replicated even within a single coaching relationship. This shows potential for future critical-moment research into other coaching relationships.

First, we have demonstrated here well-above-chance agreement in the independent selection of critical moments by coach and client (Hypothesis 1). Second, we have demonstrated significant differences between client and coach descriptions (Hypothesis 2), even though they often referred to broadly the same moments as being critical (Hypothesis 1). Third, we have found different patterns in coaching conversations away from, and in the vicinity of, ruptures (Hypothesis 3), and, for the first time, longitudinal patterns over time that bear similarities with the dose-effect relationships that have been found in psychotherapy (Howard et al., 1986; Hypothesis 4). This confirms the importance of recognizing the client experience in coaching as being different from the coach's experience, and the importance of recognizing phenomena that are related to the beginning, middle, and end stages of a coaching journey.

For us, the most encouraging finding was the similarity of experience of both persons in the room (Hypotheses 1 and 3), which disconfirms the "Rashomon conjecture" of entirely different recollections in helping relationships (Mintz et al., 1973). This finding opens the road to the possibility of real empathic understanding, compassion, mutual learning, and a shared working alliance, plus the possibility of shared understanding of the outcomes of coaching sessions. These are core conditions for the efficacy of a coaching assignment and therefore need to be demonstrated clearly and objectively in order to validate executive coaching work.

\section{References}

Allen, T. D., Eby, L. T., Poteet, M. L., Lentz, E., \& Lima, L. (2004). Career benefits associated with mentoring for protégés: A meta-analysis. Journal of Applied Psychology, 89, 127-136. doi:10.1037/00219010.89.1.127

Baron, L., \& Morin, L. (2009). The coach-coachee relationship in executive coaching: A field study. Human Resource Development Quarterly, 20, 85-106. doi:10.1002/hrdq.20009 
Berglas, S. (2002, June). The very real dangers of executive coaching. Harvard Business Review, 80, 86-92.

Boyce, L. A., Jackson, R. J., \& Neal, L. J. (2010). Building successful leadership coaching relationships: Examining impact of matching criteria in a leadership coaching program. Journal of Management Development, 29, 914-931. doi:10.1108/02621711011084231

Breuer, J., \& Freud, S. (1895). Studien über Hysterie [Studies on hysteria]. Leipzig, Germany: Franz Deuticke.

Day, A., de Haan, E., Blass, E., Sills, C., \& Bertie, C. (2008). Coaches' experience of critical moments in the coaching. International Coaching Psychology Review, 3, 207-218.

de Haan, E. (2008a). "I doubt therefore I coach" - Critical moments in coaching practice. Consulting Psychology Journal: Practice and Research, 60, 91-105. doi:10.1037/1065-9293.60.1.91

de Haan, E. (2008b). "I struggle and emerge" - Critical moments of experienced coaches. Consulting Psychology Journal: Practice and Research, 60, 106-131. doi:10.1037/1065-9293.60.1.106

de Haan, E. (2008c). Relational coaching - journeys towards mastering one-to-one learning. Chichester, UK: Wiley.

de Haan, E., Bertie, C., Day, A., \& Sills, C. (2010a). Critical moments of clients of coaching: Towards a "client model" of executive coaching. The Academy of Management Learning \& Education, 9, 607-621. doi: 10.5465/AMLE.2010.56659879

de Haan, E., Bertie, C., Day, A., \& Sills, C. (2010b). Critical Moments of clients and coaches: A directcomparison study. International Coaching Psychology Review, 5, 109-128.

de Haan, E., Duckworth, A., Birch, D., \& Jones, C. (2012). Executive coaching outcome research: The contribution of common factors such as relationship, personality match and self-efficacy. Unpublished manuscript in review.

de Haan, E., \& Nieß, C. (2011). Change through executive coaching. Training Journal, 7, 66-70.

Ely, K., Boyce, L. A., Nelson, J. K., Zaccaro, S. J., Hernez-Broome, G., \& Whyman, W. (2010). Evaluating leadership coaching: A review and integrated framework. The Leadership Quarterly, 21, 585-599. doi: 10.1016/j.leaqua.2010.06.003

Evers, W. J. G., Brouwers, A., \& Tomic, W. (2006). A quasi-experimental study on management coaching effectiveness. Consulting Psychology Journal: Practice and Research, 58, 174-182. doi:10.1037/10659293.58.3.174

Freud, S. (1905). Bruchstück einer Hysterie-Analyse [Fragment of an analysis of a case of hysteria]. Monatsschrift für Psychiatrie und Neurologie, 18, 285-310.

Hall, D. T., Otazo, K. L., \& Hollenbeck, G. P. (1999). Behind closed doors: What really happens in executive coaching. Organizational Dynamics, 27, 39-53. doi:10.1016/S0090-2616(99)90020-7

Howard, K. I., Kopta, S. M., Krause, M. S., \& Orlinski, D. E. (1986). The dose-effect relationship in psychotherapy. American Psychologist, 41, 159-164. doi:10.1037/0003-066X.41.2.159

Kombarakaran, F. A., Yang, J. A., Baker, M. N., \& Fernandes, P. B. (2008). Executive coaching: It works! Consulting Psychology Journal: Practice and Research, 60, 78-90. doi:10.1037/1065-9293.60.1.78

Landis, J. R., \& Koch, G. G. (1977). The measurement of observer agreement for categorical data. Biometrics, 33, 159-174. doi: $10.2307 / 2529310$

Levenson, A. (2009). Measuring and maximizing the business impact of executive coaching. Consulting Psychology Journal: Practice and Research, 61, 103-121. doi:10.1037/a0015438

Lowman, R. L. (2001). Constructing a literature from case studies: Promise and limitations of the method. Consulting Psychology Journal: Practice and Research, 53, 119-123. doi:10.1037/1061-4087.53.2.119

Lowman, R. L., \& Kilburg, R. R. (2011). Guidelines for case study submissions to Consulting Psychology Journal: Practice and Research. Consulting Psychology Journal: Practice and Research, 63, 1-5. doi: $10.1037 / \mathrm{a} 0021242$

Mackrill, T. (2011). The case of "Jane and Joe": A diary-based, cross-contextual case study. Pragmatic Case Studies in Psychotherapy, 7, 187-229.

McGovern, J., Lindemann, M., Vergara, M., Murphy, S., Barker, L., \& Warrenfeltz, R. (2001). Maximizing the impact of executive coaching: Behavioural change, organizational outcomes, and return on investment. The Manchester Review, 6, 1-9.

Mintz, J., Auerbach, A. H., Luborsky, L., \& Johnson, M. (1973). Patients', therapists' and observers' views of psychotherapy: A “Rashomon" experience or a reasonable consensus? British Journal of Medical Psychology, 47, 319-334.

Olivero, G., Bane, K. D., \& Kopelman, R. E. (1997). Executive coaching as a transfer of training tool: Effects on productivity in a public agency. Public Personnel Management, 26, 461-469.

Peterson, D. B. (1993). Measuring change: A psychometric approach to evaluating individual coaching outcomes. Presented at the annual conference of the Society for Industrial and Organizational Psychology, San Francisco. 
Present, J., Crits-Christoph, P., Connolly Gibbons, M. B., Hearon, B., Ring-Kurtz, S., Worley, M., \& Gallop, R. (2008). Sudden gains in the treatment of generalized anxiety disorder. Journal of Clinical Psychology, 64, 119-126. doi:10.1002/jclp.20435

Rice, L. N., \& Greenberg, L. S. (Eds.). (1984). Patterns of change: Intensive analysis of psychotherapeutic process. New York, NY: Guilford Press.

Schlosser, B., Steinbrenner, D., Kumata, E., \& Hunt, J. (2006). The coaching impact study: Measuring the value of executive coaching. International Journal of Coaching in Organizations, 4, 8-26.

Smither, J. W., London, M., Flautt, R., Vargas, Y., \& Kucine, I. (2003). Can working with an executive coach improve multisource feedback ratings over time? A quasi-experimental field study. Personnel Psychology, 56, 23-44. doi:10.1111/j.1744-6570.2003.tb00142.x

Stern, D. N. (2004). The present moment in psychotherapy and everyday life. New York, NY: Norton.

Stewart, L. J., Palmer, S., Wilkin, H., \& Kerrin, M. (2008). The influence of character: Does personality impact coaching success? International Journal of Evidence Based Coaching And Mentoring, 6, 32-42.

Tallman, K., \& Bohart, A. (1999). The client as a common factor: Clients as self-healers. In M. A. Hubble, B. L. Duncan, \& S. D. Miller (Eds.), The heart and soul of change: What works in therapy (pp. 91-131). Washington DC: American Psychological Association. doi:10.1037/11132-003

Tang, T. Z., \& DeRubeis, R. J. (1999). Sudden gains and critical sessions in cognitive- behavioral therapy for depression. Journal of Consulting and Clinical Psychology, 67, 894-904. doi:10.1037/0022-006X.67.6.894

Tang, T. Z., DeRubeis, R. J., Hollon, S. D., Amsterdam, J. A., \& Shelton, R. C. (2007). Sudden gains in cognitive therapy of depression and depression relapse/recurrence. Journal of Consulting and Clinical Psychology, 75, 404-408. doi:10.1037/0022-006X.75.3.404

Thach, E. C. (2002). The impact of executive coaching and 360 feedback on leadership effectiveness. Leadership \& Organization Development Journal, 23, 205-214. doi:10.1108/01437730210429070

Wampold, B. E. (2001). The great psychotherapy debate: Models, methods and findings. Mahwah, NJ: Lawrence Erlbaum.

Wasylyshyn, K. M., Gronsky, B., \& Haas, W. (2006). Tigers, stripes, and behavior change: Survey results of a commissioned coaching program. Consulting Psychology Journal: Practice and Research, 58, 65-81. doi:10.1037/1065-9293.58.2.65

Weiss, I., Rabinowitz, J., \& Spiro, S. (1996). Agreement between therapists and clients in evaluating therapy and its outcomes: Literature review. Administration and Policy in Mental Health, 23, 493-511. doi:10.1007/ BF02108686

Yalom, I. D., \& Elkin, G. (1974). Every day gets a little closer: A twice-told therapy. New York, NY: Basic Books.

Yin, R. K. (1994). Case study research: Design and methods. Thousand Oaks, CA: Sage. 


\section{Appendix}

\section{Literal Descriptions of Critical Moments}

In this section, we provide the full case study in the words of client and coach, literally copied from the original critical-moment descriptions, with only a few identifying details changed or omitted in the text.

Session 1: Client critical moments

There were two critical moments for me in this session:
The first critical moment for me was introducing the topics that could be discussed in the coaching as a whole and this session in particular. I was very unsure of what was expected of me in the situation, and since there was hardly any reaction from the coach's side, I felt very insecure if these were the "right" topics. I also felt like they were a bit "unimportant" compared to what the coach probably usually talked about in his sessions with other clients. It turned out that one of the topics I introduced was not really useful for coaching at that moment, which was a good insight already. Furthermore, it felt extremely strange to me to introduce such personal issues to someone who is pretty much a stranger to me.

The second critical moment was something the coach reflected to me. I had been talking about career options quite a bit at that point, and the coach then reflected to me that he felt like I really knew what I was striving for and what goals I wanted to and didn't want to achieve. This wasn't at all what was going on inside of me, because I felt like I was ruminating quite a bit about the options I had. It was very insightful to get the feedback that I didn't make this impression on someone else, but actually the opposite.
Session 1: Coach critical moments

I am struck by how easy it is for me in going back to coaching sessions thinking about what was critical, to focus on the consequences of what I have just said: the response of the client, or even, if I am brutally honest, the quality of my own intervention. To put it more succinctly: I think my memory of sessions is very biased towards what $I$ said and what $I$ thought during the session. I should try to practice more "trial identification" (Casement, 2002) in registering what the client is saying or doing when things are critical.

The critical moments in this first session were around moments that I almost "come too close." I experienced a professional, ambitious, reflective "persona" in front of me. This Christiane would like to receive reflections on her thesis and her career. Underneath I experience more anxiety, particularly around "will you not come too close?" Once I felt provoked to comment on this, and then I said "the face you pull" which is an uncharacteristically strong expression which I immediately regretted. 
Phenomenological analysis of the critical-moment descriptions: Coach and client are clearly still finding their feet with the new arrangement. The client is thinking about what is expected of her, the coach seems self-aware in his focus on how he is biased in writing up his critical moments. The coach is using some jargon (e.g. trial identification). The client has two critical moments; the coach mentions one. For the client, there seems to be some anxiety around beginning in the coaching; for the coach, around coming too close. The client achieves insight through feedback on how she comes across.

Session 2: Client critical moments

The beginning of the session was a critical moment for me. Neither the coach nor I started the conversation at first, so I felt under pressure to set the agenda for the session. I would have liked to avoid deciding what we were going to talk about, because I trusted the coach to decide which topics we had discussed in the previous session were worth continue talking about. Although I know it's probably the better approach to let the client decide on the agenda, the silence still made me feel uncomfortable and insecure whether I would raise the right topics.

Another critical moment for me occurred when the coach reflected back and interpreted something I had said: I mentioned that I was considering applying at a consultancy because I would feel like it would be a good reference in my $\mathrm{CV}$ and thus help my career in the longer run. He replied that I thus wanted to be a "Big Player" in business (or a similar expression). I had never seen myself striving to be a "Big Player" anywhere, so I felt almost offended by the comment. However, I was glad that he reflected back to me what impression my words had made on him, although I hadn't intended to do so. It made me self-reflect on the question why I would say that, and if maybe it wasn't all that far away from the truth after all.
Session 2: Coach critical moments

I think there were two or three times in this session when Christiane said "that is a good question" so I suppose those are indications of something critical happening. I cannot remember any longer when these moments occurred, exactly. Also when I checked where we were, saying "it is now halfway the session, how is it going," she said "insightful" and I think that was genuinely meant.

I was intrigued by a few paradoxes we discovered. Christiane seems at the same time very successful - in her peer group of MSc students-and young, i.e., inexperienced, so she feels she has to be bold and modest at the same time. There was another paradox about "being a loyal team player" (as in basketball) and "wanting to be different/distinct" (as in having other occupations from fellow students and highlighting her difference in that choice). We may be getting closer to where the ambivalence is.

Phenomenological analysis of the critical-moment descriptions: The two moments from the client seem similar to those in the first session, the first suggesting some anxiety about what is expected of her or how she can lead this coaching relationship, and the second showing some insight through feedback (or in this case a summary plus interpretation of the critical-moment descriptions) from the coach. The client also writes about the emotional (somewhat painful) impact of this learning process ("I felt almost offended ... however, I was glad"). In this the client wrote about her ambivalence and it is striking that the coach mentions ambivalence as well. 
In addition, in the comments of the coach, there are some similarities with the first session. Again, the coach couches some of his language in jargon (e.g., "getting where the ambivalence is"). Following his own realization after the first session that he is overly central to his own critical moments, he now tries to find something critical in the responses of his client, responses like "good question" and "insightful." There seems to be no identified critical moment for the coach.

Session 3: Client critical moments

I started out the session introducing a topic that we hadn't talked about in the previous session. It had to do with me finishing one stage of my life to go back to what I had previously done. When I started talking about it, I noticed how I became nervous, started blushing, my voice became shaky, and tears came to my eyes. I was surprised to notice those symptoms, because I hadn't been aware of the fact that the topic was an emotional one to me. This was definitely a critical moment for me. Talking to the coach about why this evoked such strong emotions inside me definitely made me realize that it had a more underlying reason that I hadn't been aware of. The initial emotional reactions just lead to a more rational understanding of the topic, which helped me to work through it with the coach.
Session 3: Coach critical moments

I thought there were a lot of emotions around particularly at the beginning of the session. I saw red color on your face. I thought you were just very grateful for the time you had had at one research project, very satisfied about what it gave you. I felt very moved at the beginning of the session. I may have misread the emotion. I regret I didn't ask you what it was about. I probably didn't dare asking and felt protective of the "bubble" or "bubbly feeling." I did not want to burst the bubble.

Phenomenological analysis of the critical-moment descriptions: Both client and coach descriptions are much shorter than those for the previous two sessions. They both point to exactly the same moment a few minutes into the session, an emotional moment that remained unexpressed verbally, but that had clearly touched both coach and client. Following the felt emotions, the client reports a critical moment that is of a different nature as in the previous sessions, a moment of "working through" with the help of reflection. 
Session 4: Client critical moments

The critical moment of this session was a change in my perception of the relationship to the coach. While we were discussing, we proposed to me an interpretation of a situation which was less favorable to me, namely, that I had felt some kind of jealousy. While I was first reluctant to discuss this option openly, I noticed that I had indeed built enough trust in my coach over the past few sessions that I was able to consider his idea and admit that he was right. I felt like this took the conversation a lot further and deepened the conversation as well as the relationship to the coach. It was a very honest conversation, and I was thankful that the coach had not been holding back, reluctant to express his interpretation of the situation.
Session 4: Coach critical moments

A session about competition and ambition, as related to the tasks you are engaged in and the layers of relationships that you need to manage. Very tough for you and I hope I haven't been too tough as a response. In fact, I felt very caring, careful and "parental."

Critical moments:

(1) I did once feel the competition flaring up between the two of us as well. A difficult moment. It was in the beginning of the session when you related how you had mentioned some prominent consultancies that you are involved with. I then laughed rather loudly and you said "What? What?" rather anxiously_upon which I said, "Big Names. You dropped some 'Big Names' with them." I think you were again sensitive in the here and now, this time about my response to you.

(2) I think it was a relief for you to hear from me that "yes you might be projecting out ambition and competition while you are also quite competitive yourself-and there is nothing wrong with that." You had pondered on how competitive you were and how much you were suppressing this. I think it was somehow better for you to acknowledge yourself as competitive, envious, desiring to impress, etc., rather than placing that in other people. Hopefully it will help you to take a bit of detachment (relax, smile) from this as a next step.

I am wondering why I am writing in the second person to "you" I think it is because I am making these notes still within the session time, i.e., straight after the session ended prematurely after your phone ran out of battery.

Phenomenological analysis of the critical-moment descriptions: This time, the length of the writing of client and coach is dissimilar, with the coach writing a much longer piece. The client's critical moment is again of a different order, as it is more related to the relationship she experiences with the coach, which has enabled her to hear feedback. As before, open and frank feedback appears to lead to insight, or at least to a new perspective. Similarities are that both client and coach report a deepening of the relationship, which the coach seems to underline by continuing to write in the second person, and that coach and client apparently write about one critical moment that they both experienced: the acknowledging of competition and jealousy/envy. Again, there are hints of an emotional learning process for the client. 
Session 5: Coach critical moments

\footnotetext{
For me this coaching session involved two critical moments. The first moment occurred somewhere in the middle of the session. We had been talking about career options in the previous sessions, exploring what I was able to apply for after finishing my studies. I had been holding the assumption that I could do pretty much anything I wanted. However, prior to this session, I had been turned down for a workshop I had applied for. While I saw this as a "one-timer," something that had never happened to me and wouldn't happen again, the coach offered a different interpretation. He made me aware of the fact that by choosing a Research Master program, I had limited my career opportunities. This was also an explanation of me procrastinating on my application for another position. I highly valued this new view on the matter, as it opened my eyes to something I probably simply didn't want to see before.

The other critical moment occurred at the very end of the session. The coach had been a bit late for the session, and at the end of it he suggested that maybe there was a subconscious reason for him being late. This idea was a bit in line with what we had talked about during the session, that sometimes it is not obvious what underlying reasons for our actions are. Although I appreciated the coach's honesty in this particular moment, I also made me feel a bit uncomfortable. Was I a difficult client? Was I boring him during the sessions? I think hadn't this moment occurred at the very end of the session, it would have influenced the course of the session in a negative way, because it would have made me a bit more hesitant.
}

In spite of my being late I thought this was a really rich session, particularly thanks to your openness and willingness to hear quite challenging feedback.

The first critical moment was obviously my being late, in particularly the moment when I discovered I was not simply going to be 2 minutes late (as I let you know), but I was going to be 15 minutes late. I felt guilt, I also immediately asked myself why I was permitting myself such an infringement, a breaking of boundaries, when I would never allow myself to do that with a "real," i.e., "full fee paying" client.

The second critical moment was obviously when I shared that with you at the end of our session, and I was vulnerable and questioned my own motives just like I had questioned yours. I wondered what you were making of that.

There was another critical moment for me when I checked with you "how I can help" with regard to the two issues you introduced at the very beginning of the session. You said with regard to the first one, "I feel already helped a great deal, by recognizing some of my own ambition and drive." That was such positive feedback, I felt the session was already a success even if it was still relatively early into the session. I did check towards the end whether we had really taken enough time for the first issue, and you reassured me again. 
Phenomenological analysis of the critical-moment descriptions: The session is clearly heavily influenced by a boundary infringement at the very beginning, even if a small one: "the coach was a bit late" in the words of the client. It shows us never to underestimate the effects of boundary issues in coaching. This one turns out to have major repercussions in the next two sessions as well (see below). Both client and coach critical moments refer to the lateness of the coach, although the client seems unaffected until the coach raises it later in the session. Again, in the first client critical moment, a new perspective (a frank view from the coach) leads to insight. The second client critical moment builds on the theme of the deepening relationship from the previous session, showing how a coaching relationship is never a given, a fact, but that it is always evolving and changing, and that ruptures are never far off even in well-established coaching relationships. We see both client and coach wondering how they are coming across to the other, and we see the coach still affected by self-doubt even when receiving very positive feedback (his third critical moment).

Session 6: Client critical moments
The critical moment of the session occurred
somewhere in the end of our session. Not
much had happened on the topics that we
had been discussing in previous sessions, so
I didn't really "bring much" to the
conversation. The coach noticed this as well
and mentioned it to me. What followed was
a very honest but difficult conversation. As
mentioned in the critical-moment description
of the last session, there had been a
comment that made me quite conscious of
my inferior role in the relationship. I had
however not decided to address this. The
coach offered the suggestion that this feeling
of me being inferior, unimportant, or boring,
probably was something that I experienced
in other relationships as well. Unfortunately,
we weren't able to discuss this further,
because we had reached the end of the
session. However, I felt like it was a very
honest moment. It made me realize that the
coach noticed such underlying things as
well. Although I found his interpretation a
bit hurtful, I appreciated him noticing and
mentioning it to me. I think it will probably
help to discuss this in the following
sessions.

Session 6: Coach critical moments

This was a really tough session I think for both of us, certainly for me.

The first really critical moment occurred when you said "I am just... unimportant. My work is. . . unimportant. I must be different from your other clients, as I am 'just' a student. Coaching with me must be quite boring for you." You said these thoughts were triggered by me saying there may have been an unconscious reason on my part for my being late at our previous session. And you added that it felt like a rupture, then.

Then for me there was a second critical moment when you said, "I cannot pay you for the work," and in the same breath, "This coaching is only for your research," implying the coaching was not really for you but rather for me and you wouldn't be able to afford it anyway. It felt like you were really angry with me, and like you were accusing me of being disinterested, or rather of being self-interested, and of not being able to keep you in mind or be interested in you. I remember I was so taken aback that I said things like "you are doing just fine," "this is not boring to me," and "it is wonderful that you are paying a charity for this work" (in other words, I was arguing back: "you are paying for this"). I got so wrapped up in defending the coaching that I wasn't coaching anymore. 
I am really curious as to where this will take us next time. Hopefully you will learn something about your desperation and your anger. At the moment you will probably not feel you have learned anything. Another rupture.

If I think back again I notice lots of other critical moments as well, before these two, which occurred towards the end of the session. So these are earlier in the session:

(1) How I gave you a tough challenge when I said you hadn't been very proactive regarding this session and perhaps you could be more proactive as well regarding the dependencies you are experiencing in your MSc-work.

(2) How I felt self-doubt when contemplating if I should suggest finding rooms with a commercial assessment center provider (which in the end I did - and it made little difference). I felt this would be too advisory to be coaching.

Phenomenological analysis of the critical-moment descriptions: The session is still highly influenced by the boundary problems identified in the previous session and by the various ways of mentally dealing with the "issue," independently by coach and client, to the point that we can infer that there was a rupture or a near-rupture in their work together during this session, with feelings of humiliation and anger on the side of the client, and of panic and embarrassment on the side of the coach. Both client and coach write this theme up as one big critical moment, to which the coach adds two others from earlier in the session. One is a hunch of some possible further "insight through feedback" and the other is a fairly common doubting process around whether or not to offer advice as a coach. Fairly typically, the advice when offered (as is also usually the case when not offered) makes very little difference. 


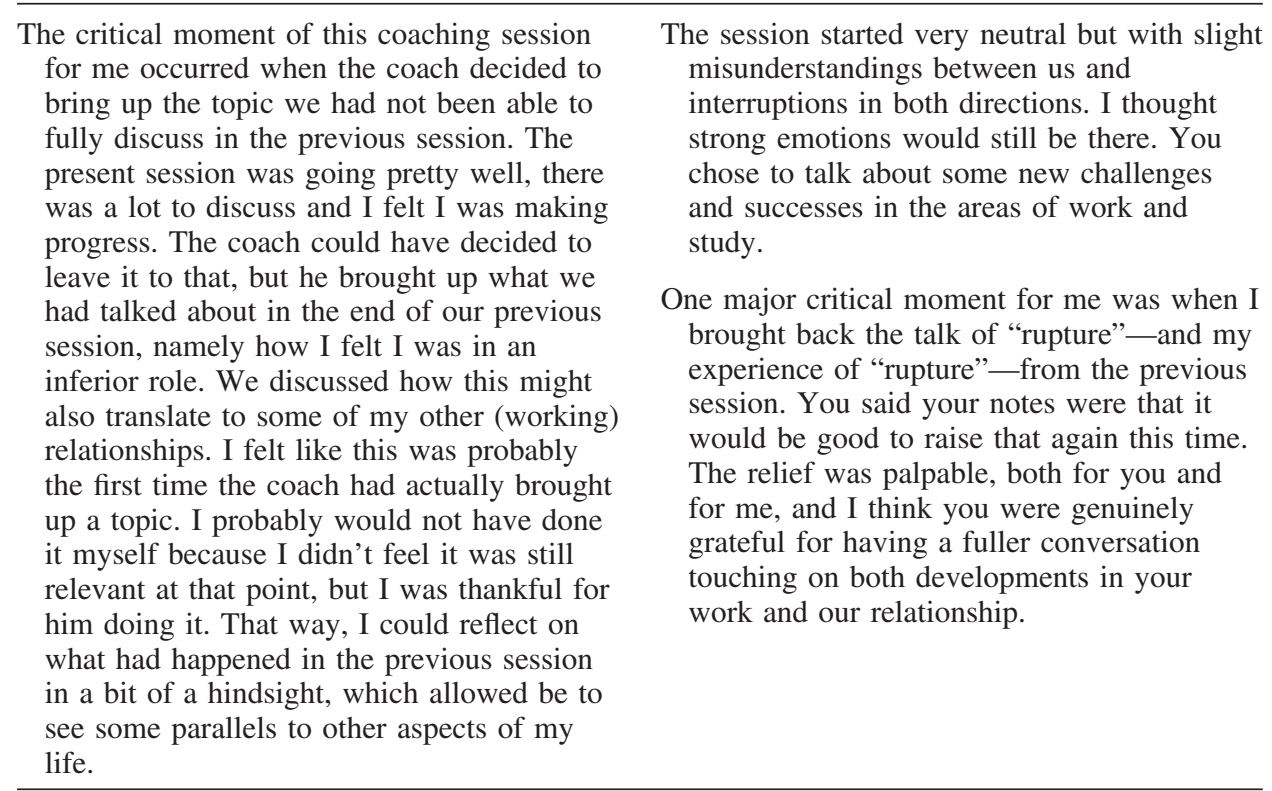

Phenomenological analysis of the critical-moment descriptions: The one critical moment mentioned by both is exactly the same for coach and client, and harks back to the boundary infringement identified two sessions previously, to the near-ruptures of the previous session. Both client and coach comment on how the decision of the coach to bring up the issue and their relationship again makes a difference within the relationship and leads to new insight on parallel processes in other areas. Gratitude is mentioned by both client and coach. 
Session 8: Coach critical moments

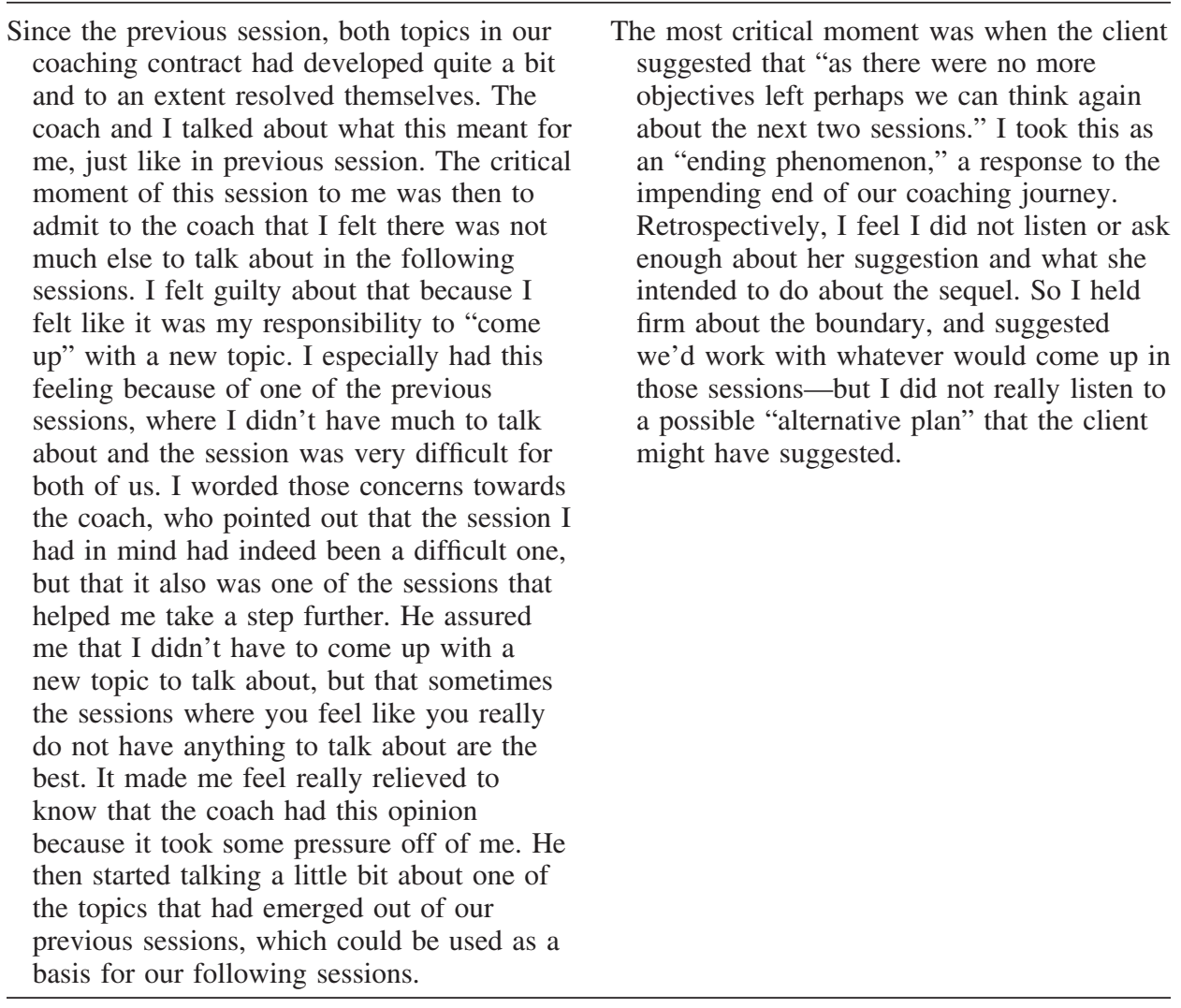

Phenomenological analysis of the critical-moment descriptions: Once again, the single critical moment mentioned by coach and client is clearly the same: the discussion about running out of steam and the sense of having completed the contract already. Both coach and client seem to feel slightly guilty about the handling of this moment. 
Session 9: Client critical moments

To me it felt like there was not one distinct critical moment in this session. Rather, I felt like there were several, similar moments that felt critical to me. In all of those moments, the coach gave me some kind of an insight that I could have seen as threatening to my ego. There are two reasons why this made those moments critical to me. First, it showed that the coach felt comfortable sharing his insights with me, although they could have meant a rupture for our relationship. Second, I noticed that his comments did not offend me, although they were quite strong. Coming from any other person, I would have probably been hurt and would have walked away from the conversation. In this case, I however tried to explore together with the coach where his comments were coming from and whether there was some truth in them for me. These two reasons together made the moments critical to me, as they showed that our relationship was trustful enough to both make and receive honest remarks like that.
Session 9: Coach critical moments

What was critical about this session was that Christiane reminded us at the beginning of the session that we were now strictly "outside of the contract" as the two areas that we embarked on "were now resolved" or had now moved on. There was less of a sense of urgency about this session than about some of the other sessions. This is a general sense, not a specific moment. In retrospect I feel I should have offered more space, more listening and silences in order for other things to emerge

My most critical action during the session was for me the challenging move from "treating us like children" (which is what Christiane reported) to "a childish response to others" (which I alleged Christiane may have, pointing to her own possible share in the "treating us like children"). I did this as gently as possible, but fear I may have bruised or lost her in the process - and I also wonder if there would have been more mileage in exploring more deeply the "treating us like children" bit, staying with what Christiane actually brought to the session.

Phenomenological analysis of the critical-moment descriptions: Interestingly, both coach and client mention, for the first time, that there were no critical moments in the session, as, according to the client, there were "several similar moments," and, according to the coach, "more of a general sense less of a critical moment." Both client and coach write about the coach feeling confident to honestly share his "insights" (client)/"challenges" (coach), even though they "could have led to a rupture" (client)/"may have bruised or lost the client" (coach). This is taken, at least by the client, as evidence for a strengthening coaching relationship (or perhaps as a full recovery of the coaching relationship after the major rupture in Sessions 5 and 6). 


\begin{abstract}
There were two moments in the session that I experienced as critical. The first moment was actually more of a time-span quite early in the session. I had introduced a topic that we had only discussed very briefly in a preceding session. Once I had explained the situation to the coach, it seemed to me like he paraphrased and interpreted what I had said and then gave me advice on how to

It was fascinating that the first "topic" was all about becoming a practicing occupational psychologist and what that means for how people will see Christiane, and about "setting up practice" as an organizational psychologist. Although Christiane said she hadn't realized this was an ending session, this topic seemed appropriate as it was related to "going out into the wider world."
\end{abstract} deal with this issue. This was quite a new feeling for me, because I felt like in the previous sessions, he had been more reluctant to provide me with any kind of expert opinion. I didn't feel like it was out of line at all, rather I was thankful for his advice. I did however notice it as some sort of change in the coach's role.

The second moment occurred when we had finished talking about the first, new topic that I had introduced. The coach then asked me about some of the other topics we had talked about in the previous sessions. What was critical to me was that he seemed to remember so many details of what I had told him, such as names of people involved. This made me feel very honored and as if the coaching, or the coaching relationship, really was something important not only for me, but also for the coach.
The only critical moment I experienced was when I found myself talking so much, when we had returned to the theme of being "junior" and slowly moving up the ranks, the theme of dependence on and perceived inferiority to more senior people. I found myself unable to stop talking or associating with that theme, and wondered if it was more my theme than Christiane's.

Phenomenological analysis of the critical-moment descriptions: An ending session where coach and client really part ways. For the first time in eight sessions, the critical moments appear unrelated and the perspectives are different. The client's critical moment is different from earlier ones, as it is related to "getting advice from the coach." There is some overlap still, as both client and coach notice that that the coach has been more forward and directive during this session, by, for example, "giving advice" (client) and "being unable to stop talking" (coach).

Shortly after the 10th and last session, the notes of client and coach were e-mailed across and shared, and, on the same day, both coach and client formulated a first response to reading the other person's critical-moment descriptions. We give those initial responses here in full, for completeness and also because they provide a good initial summary of relational themes in this coaching journey. However, it is good to point out that in this case the coach's response was written after reading the client's response, so here the right-hand column is not independent and partly a response to the left-hand column: 
The first overall impression that struck me was that there are so many doubts expressed in your descriptions. I guess I should have expected that, considering your previous research, but somehow I didn't. You write a lot about whether something that you said or did was right or wondering whether you could have done something differently. To be quite honest, I actually did notice some of those moments as well, but I was under the impression that you actually consciously and deliberately initiated those. For example, the critical moment you describe in the very first session, you write that you said something about "the face I pulled." I did notice that phrase as something critical as well, but I actually thought you deliberately tried to provoke me with that.

I find it very interesting that you change the style of writing in between, changing from 3rd to 2nd person narrative and back. I wonder why that is the case, but don't really have any assumptions or ideas about it. You raise it as a question as well though.

Another thing I noticed was that you seemed to have some idea of where we were heading from the very beginning. You write something about ambivalence, which is sort of what we ended up talking about a bit more. I wonder whether those impressions you had in that second session were true, so that we ended up talking about them, or whether it guided you to lead our conversations in that direction.

I find it striking how similar some of our descriptions are, for example the 3rd session, 6th session, and the 8th session, the latter having almost no critical moments.
When I look at your critical-moments descriptions, I am struck by the following:

The range of your experience of me as a coach, all the way from "abstinent" in session 1 to "advisory" in session 10. For me there was probably less of a range as I tried to facilitate your own development all along.

I feel more confident now than I did when we were working together, that we were mostly working on relevant and important themes. I take that e.g. from your statements "I felt they were a bit unimportant" and "one of my topics was not really useful" in your very first session note-which are already hints towards bigger themes such as "feeling unimportant" in later sessions.

Your notes made me think again of the importance of coaching for "learning about the impressions one makes," in other words for "getting feedback" or "participating in a self-reflective relationship"- -aspects of coaching that are often considered secondary but strikingly important from some of your notes. 
It feels like the moments that refer to a "metalevel" are especially interesting. If you look at the 5th session, for example, we both describe a moment that is about the coaching itself, and didn't occur within the coaching. It seems like we both felt it was critical to consider this meta-level, and we both describe that it was important to do so. I see similar patterns in both our descriptions of the 7th session.
I love your slip when you write "we proposed to me" (in Session 4), which I take as a very concise description of some of our best work together.

I think some of our work must have been quite challenging for you (and for us both) and I admire your courage of staying with it and staying with this reflection on it as well.

My hypothesis about a possible unconscious reason for my coming late for two sessions is not a reflection on you or the material (as you suggest), more on the multiple bonds that existed between us, which have perhaps made me feel more confident that both of us would stick to the coaching contract even if there were going to be difficulties, because we both had ulterior motives to do with the research work we were doing together. In other words, I think I was just more confident that you would wait for me than I would have been with other clients. 


\section{AUTHOR QUERIES}

\section{AUTHOR PLEASE ANSWER ALL QUERIES}

AQau-Please confirm the given-names and surnames are identified properly by the colors. = Given-Name, $\boldsymbol{a}=$ Surname The colors are for proofing purposes only. The colors will not appear online or in print.

AQ1- Au: As per APA style please limit your list of keywords to no more than 5 words/concepts.

AQ2 - Au: In the sentence beginning "The following is an overview," please provide a citation and page number for the quotation.

AQ3 - Au: The syntax of the sentence beginning "Content analysis showed that clients" seems awkward, and the sentence is therefore difficult to understand. Please reword for clarity.

AQ4- Au: In the sentence beginning "De Haan et al. (2010b) collected descriptions," the last part of the sentence ("no longer taken...chosen by the respondents") is difficult to understand. Please revise for clarity.

AQ5- Au: As per APA style, "dataset" was changed to "data set" throughout.

AQ6 - Au: As per APA style, when used as a noun, United Kingdom should be spelled out. When used as an adjective, the abbreviation is used. This has been changed throughout.

AQ7- Au: Upon first mention in the text, please spell out MSc in full; thereafter, the abbreviation may be used.

AQ8 - Au: In the sentence beginning "Although coaches most often report," please indicate whether the de Haan et al. (2010) citation should be 2010a or 2010b.

AQ9- Au: In the Limitations and Directions for Future Research Section, there are citations for de Haan (2010a) and de Haan (2010b). Please indicate whether these should be de Haan et al. for those dates, or de Haan 2008a and b. Please note that the citations occur in two separate paragraphs of this section.

AQ11- Au: Please confirm whether de Haan \& Niess (2011) has a volume number, or if not, an issue number.

AQ12- Au: For Freud (1905), please confirm whether " 4 " is the correct page number and that there should not be additional pages listed. 


\section{AUTHOR QUERIES}

\section{AUTHOR PLEASE ANSWER ALL QUERIES}

AQ13 - Au: Please provide both a title for your appendix and for the table.

AQ14- Au: Section 8 information was repeated in the appendix and has been removed. Please confirm that this is correct. 